\title{
Development of a tension pneumothorax despite intercostal drain insertion
}

\author{
Alasdair James Scott, ${ }^{1}$ Sean J Davies, ${ }^{2}$ Pantelis Vassiliu ${ }^{3}$
}

${ }^{1}$ Imperial College School of Medicine, Imperial College London, London, UK 2Department of Faculty of Medicine Nursing and Health Sciences, Monash University,

Victoria, Australia

${ }^{3}$ Department of Fourth Surgical

Clinic, Attikon University

Hospital, Athens, Greece

Correspondence to

Dr Alasdair James Scott, as703@ic.ac.uk
To cite: Scott AJ, Davies SJ, Vassiliu P. BMJ Case Reports Published online:

4 December 2012

doi:10.1136/bcr-2012 006358

\section{DESCRIPTION}

A 21-year-old man presented to a trauma department in Johannesburg with two sucking stab wounds on each side of his posterior thorax. The patient was in respiratory distress with oxygen saturation of $91 \%$ on $15 \mathrm{~L} \mathrm{O}_{2}$. Blood pressure was $105 / 72 \mathrm{~mm} \mathrm{Hg}$, pulse 112/min and blood gas analysis demonstrated a mixed metabolic and respiratory acidosis.

A left haemopneumothorax was detected clinically although there was no evidence of tensioning. The stab wounds were covered with damp, three-sided dressings and an intercostal drain (ICD) was inserted into the left hemithorax, draining $\sim 500 \mathrm{ml}$ of blood. A radiograph (figure 1) confirmed correct ICD placement but also showed a right-sided pneumothorax. Another ICD was therefore inserted and a radiograph (figure 2) was obtained to check location. We were surprised to see enlargement of the pneumothorax and significant left shift of the mediastinum suggesting the development of a right tension pneumothorax.

We considered that the ICD might not be functioning, however, this seemed unlikely as the water level was swinging with respiration and bubbles were observed on coughing. A large, unidirectional air-leak into the hemithorax could exceed the drainage capacity of the ICD at low intrathoracic pressure. This would allow a degree of air accumulation and an increase in intrathoracic pressure (until equilibrium was reached) sufficient to cause mediastinal shift. The three-sided dressings should have prevented continued external air-leak but they may not have stuck properly or could have become dislodged. In support of this theory, wound closure in two layers resulted in resolution of the pneumothorax.

\section{Learning points}

- Posteroinferior placement of intercostal drains allows drainage of any dependent fluid and air, as the latter will distribute evenly throughout the pleural cavity.

- It is possible for tension pneumothorax to develop even in the presence of a correctly inserted, functioning intercostal drain.

- If a pneumothorax persists with a drain in situ, consider failure of the drain or the presence of an on-going air-leak-either internally or externally.

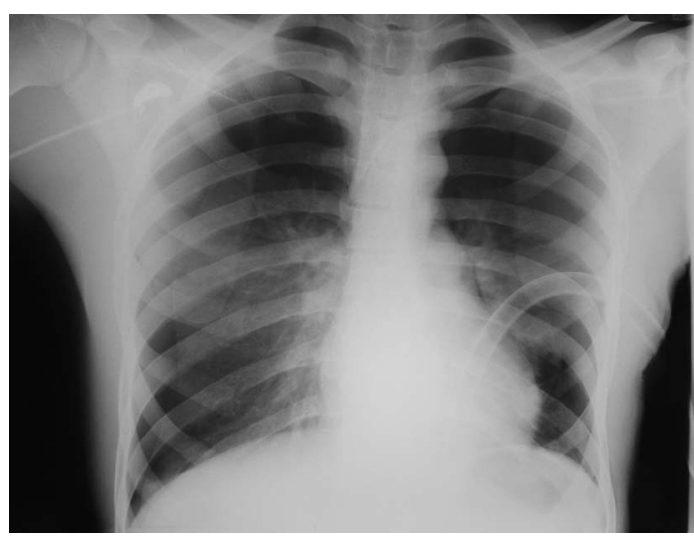

Figure 1 A correctly located intercostal drain (ICD) is visible in the left hemithorax in addition to a central venous catheter in the left subclavian vein. A pneumothorax is also visible on the right, but there is no evidence of tensioning.

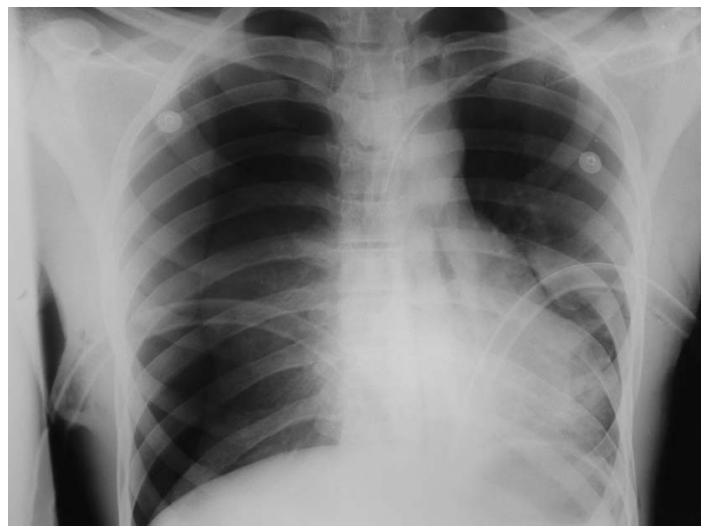

Figure 2 Following insertion of a second intercostal drain (ICD) into the right hemithorax, the pneumothorax can be seen to have enlarged and the thoracic vertebrae are prominent as the mediastinum has shifted left. The patient has developed a tension pneumothorax despite the presence of a functioning ICD.

Competing interests None.

Patient consent Obtained. 
Copyright 2012 BMJ Publishing Group. All rights reserved. For permission to reuse any of this content visit http://group.bmj.com/group/rights-licensing/permissions.

BMJ Case Report Fellows may re-use this article for personal use and teaching without any further permission.

Become a Fellow of BMJ Case Reports today and you can:

- Submit as many cases as you like

- Enjoy fast sympathetic peer review and rapid publication of accepted articles

Access all the published articles

- Re-use any of the published material for personal use and teaching without further permission

For information on Institutional Fellowships contact consortiasales@bmjgroup.com

Visit casereports.bmj.com for more articles like this and to become a Fellow 